\title{
SOCIEDAD Y DERECHO: LA INFLUENCIA DE LA ESCUELA DE FRANKFURT Y SU TEORÍA CRÍTICA EN LOS ORÍGENES DEL PENSAMIENTO DE HABERMAS
}

\author{
Society and Law: The legacy of the Frankfurt School and Critical Theory \\ in the origins thinking of the Habermas
}

\author{
Mario Durán Migliardi*
}

\section{RESUMEN}

Bajo la premisa de que la Teoría Discursiva del Derecho de Jürgen Habermas es un paradigma que contribuye a sustentar una fundamentación democrática y una legitimidad racional del Derecho, el presente artículo pretende desarrollar la influencia que, en los orígenes de la obra de Habermas, tuvieron los principales postulados de la Escuela de Frankfurt y su Teoría Crítica de la sociedad.

Palabras clave: Escuela de Frankfurt, Teoría Crítica, Teoría discursiva del Derecho, Habermas.

\begin{abstract}
Under the premise that the Discursive Theory of Law of Jürgen Habermas is a paradigm that helps to sustain a democratic fundamentation and a rational legitimacy of Law, this article develops the influence in the origins of the work of Habermas of the main postulates of the Frankfurt School and their Critical Theory of society.
\end{abstract}

Keywords: Frankfurt School, Critical Theory, Discursive Theory of Law, Habermas.

\footnotetext{
* Departamento de Ciencias Jurídicas, Facultad de Ciencias Jurídicas y Sociales, Universidad de Atacama. Copiapó, Chile. Correo electrónico: mario.duran@uda.cl

Artículo recibido el 05 de julio de 2017. Aceptado el 25 de septiembre de 2017.
} 


\section{Introducción y delimitación}

En la búsqueda de principios que contribuyan a dar sustento a una fundamentación democrática y a la búsqueda de una legitimidad racional del Derecho, en general, y con el afán de delimitar democráticamente el Derecho penal, en particular, aparece la monumental obra de Jürgen Habermas como un insumo digno de considerar.

La relevancia del análisis de Habermas -en esencia- aparece para el Derecho no solo por ser el principal autor que, de forma global y desde un materialismo histórico moderno, ha sido capaz de desnudar las distintas problemáticas del capitalismo tardío -sobre todo en aquellas sociedades que gozan de un Estado del bienestar- a partir del reconocimiento y valoración positiva de la democracia, de los Derechos Humanos y, principalmente, del propio Derecho.

La propuesta discursiva de Habermas es relevante para el Derecho porque, luego de profundas reflexiones, llega a una conclusión fundamental: el medio que tiene mayores posibilidades de cumplir la función de mediar o integrar los distintos conflictos sociales, propios de la sociedad posmoderna, es el Derecho. Esto es, la función que antiguamente cumplió la religión, la moral o la opinión pública, en la actual sociedad contemporánea, caracterizada por el riesgo (Beck, 1998), la sobre-información, la globalización económicocapitalista y por una creciente desigualdad sociocultural y económica, queda entregada al Derecho.

Más aún, en las áreas más sensibles de la modernidad, esta nueva confianza en las capacidades de control, mediación o integración que recaen hoy sobre el Derecho, ha dado origen al denominado fenómeno de la expansión del Derecho penal (Silva, 2001), hacia áreas nunca antes tratadas penalmente, tales como el medio ambiente, la seguridad social, la inmigración, los intereses difusos y los bienes jurídicos colectivos, áreas que se deben o pretenden 
controlar a través de la ley y el Derecho.

Lo mismo rige, a propósito de las permanentes discusiones sobre el rol de la Constitución y del propio guardián posmoderno de las cartas fundamentales, el Tribunal Constitucional, en la sociedad posmoderna (Habermas, 2001: 311361; Letelier, 2011).

En este marco, y dada la amplitud y complejidad de la obra de Habermas, es necesario rescatar y conocer - previamente- las que se han señalado como sus principales fuentes o antecedentes, esto es, la Escuela de Frankfurt y la Teoría Crítica (McCarthy, 1978:154; Ureña, 1978:21-58; Requejo, 1991; Ferrater, 1994:1541; Fernández, 1997; Velasco, 2000; Quiroga, 2007: 251; Kominek, 2007). Sobre todo, porque ello contribuye, a mi juicio, no solo a aclarar y resaltar el contenido profundamente democrático, humanista y libertario del discurso de Habermas sino también a comprender el verdadero significado de lo legítimo y lo válido en una sociedad moderna cada vez más compleja, pluralista y desencantada. Argumentos todos por los cuales se le ha señalado, correctamente, como uno de los pocos autores contemporáneos donde nos encontramos con esa extraordinaria capacidad para estar siempre presente en el debate intelectual y para dejarse ver a la vez en el espacio público como una verdadera conciencia moral de nuestra sociedad (Vallespín, 2001:53).

Ello implica resaltar, además, que desde las fuentes primarias materia de este trabajo -la Escuela de Frankfurt y la Teoría Crítica-, el pensamiento y la visión de Habermas sobre el Derecho y la democracia, el derecho internacional, la modernidad, así como su crítica a la razón, han evolucionado más en clave Kantiana que Hegeliana. Tanto que, como bien señala Jiménez Redondo al prologar Facticidad y Validez, su obra puede considerarse una reformulación de la filosofía del derecho de Kant y un retorno a ella, nacidos de forma bien consecuente desde dentro de la propia tradición de pensamiento de la izquierda hegeliana, una vuelta de Hegel a Kant a través de Marx (Habermas, 2001:20).

Tanto es así que, al analizar al derecho como categoría de mediación 
social entre facticidad y validez, Habermas (2001) valora y expresa un importante reconocimiento a la obra de Kant, cuando afirma:

Para Kant la relación entre facticidad y validez, estabilizada en la validez jurídica, se presenta como la conexión interna que el propio derecho funda entre coerción y libertad. Ello, porque el derecho está ligado de por sí con la facultad de ejercer coerción; pero esta coerción sólo se justifica como «un impedir que se ponga un impedimento a la libertad», es decir, sólo se justifica desde el propósito de oponerse y resistir a las intrusiones en la libertad de cada uno. Esta interna «conexión de la coerción general mutua con la libertad de cada uno» se expresa en el tipo de pretensión de validez del derecho. Las reglas jurídicas establecen condiciones de coerción, «bajo las que el arbitrio de uno pueda concertarse o conciliarse con el arbitrio del otro conforme a una ley general de la libertad» (90-91).

Más aún, respecto del contrato social, la soberanía popular y la democracia, Habermas (2001:158-159) vuelve nuevamente sobre Kant, señalando que el derecho a iguales libertades de acción, como único derecho innato del hombre, solo puede diferenciarse para Kant "en un sistema de derechos mediante el que puede cobrar forma positiva tanto «la libertad de cada miembro de la sociedad, como hombre», como también «su igualdad con todos los demás, como súbdito»»". Concepto muy cercano al propio planteamiento de Habermas sobre el sistema de derechos (2001:147).

La propia evolución en la valoración del Derecho, tema que por su necesario desarrollo escapa a los fines de este trabajo, nos muestra que desde una visión negativa basada en sus fuentes primarias -la Escuela de Frankfurt y su Teoría Crítica- (Habermas, 1992: 502) en la que se resaltan los efectos cosificadores y alienantes de la juridificación, Habermas pasa a adoptar una visión más positiva del mismo (Velasco, 2007; 2000:141-182; García, 2000). Fundamental para ello fueron sus Reflexiones sobre la posición evolutiva del Derecho moderno (Habermas, 1981: 233-240), que dieron origen a una posterior valoración positiva del Derecho como un elemento insustituible de integración social (2001:150-169), como complemento funcional de la moral racional (1998; 2001:169-184) y como un medio discursivo propio de la postmodernidad 
(1985b; 2001:184-197, 218-236). Tanto así, que incluso ha llegado a plantear la necesidad de discutir acerca de la pertinencia de una Constitución para la Unión Europea (Habermas, 2002).

Pero, ¿cómo se llegó a esta nueva visión? ¿cuáles son los planteamientos básicos de las fuentes primarias desde las que evoluciona el pensamiento de Habermas? A continuación se intenta dilucidar, en parte, tales interrogantes.

\section{La Escuela de Frankfurt}

Se ha establecido (Jay, 1986; Cortina, 1986:31; Colom, 1992:15-65) que el origen remoto de la denominada Escuela de Frankfurt se encuentra en el gran interés que despertó el estudio del marxismo en Alemania una vez terminada la Primera Guerra Mundial. En este ambiente, en el año 1922, Kurt Albert Gerlach propuso al Ministerio de Educación alemán la creación de un Instituto de Investigación Social con sede en Frankfurt, económicamente autónomo pero afiliado académicamente a la Universidad de Frankfurt. Aprobada la idea, el Instituto se fundó oficialmente en 1923, siendo su principal publicación y órgano de expresión el Zeitschrift für Sozialforschung, donde colaboraron, entre otros, Horkheimer, Adorno, Fromm, Benjamin y Marcuse.

Los problemas surgen a la hora de determinar con exactitud quiénes son o no son frankfurtianos puesto que las grandes diferencias entre los distintos autores que se adscriben a la Escuela dependen, entre otros elementos, de su mayor o menor proximidad a Marx -reflejada en su particular interpretación marxista-; de la intensidad de las preocupaciones filosóficas, sobre todo ontológicas y epistemológicas; del mayor o menor acercamiento al psicoanálisis; del tipo de pensamiento filosófico contemporáneo al que adscriban o estudien -vitalismo, fenomenología, neopositivismo, etc.-; y de la generación a la que pertenezcan. Así, no hay duda en señalar como frankfurtianos a Max Horkheimer y a Theodor W. Adorno - considerados, además, padres o fundadores 
de la Escuela- o a Herbert Marcuse y Walter Benjamin. La duda surge con autores de generaciones posteriores, como Habermas. Si se sigue un criterio amplio, como Cortina (1986: 35; 2007: 50), Habermas debe ser considerado como un frankfurtiano, porque, no obstante las diferencias entre sus ideas y preocupaciones filosóficas con respecto a las de Horkheimer y Adorno, hay grandes semejanzas en los puntos de partida y en ciertas orientaciones. Si se sigue un criterio estricto, hay que considerarlo junto a los demás autores de su generación, como una desviación fundamental con respecto a la Escuela de Frankfurt clásica.

A pesar de estas diferencias, lo importante es que entre los frankfurtianos existen características que los distinguen de otras corrientes filosóficas contemporáneas; su permanente y contundente defensa de lo que denominaron Teoría Crítica, versus la apodada Teoría Tradicional, y su fuerte oposición a la especulación filosófico-sociológica, no vinculada a problemas reales y concretos, al empirismo positivista y a la creencia en la importancia fundamental de los métodos cuantitativos. Por ello, como bien se señala, lo que realmente unifica a los miembros de la Escuela de Frankfurt, y que convierte a su filosofía y sociología en una real muestra de crítica científica concreta, es el estilo de pensar que se expresa en una incomodidad política común frente a las respectivas realidades sociales que les tocó vivir (Cortina, 1986:35; 2007: 50; Ureña, 1978: 47; Colom, 1992:178-179).

Gracias precisamente a este estilo de pensar, los miembros de la Escuela de Frankfurt han sido capaces de experimentar una importante evolución, que ha ido más allá del mero traspaso de ideas entre la primera generación-Adorno, Horkheimer, Marcuse- y la segunda generación, representada por Habermas. En virtud de ella, ya los primeros, cambiaron sus puntos de vista y desarrollaron su propia filosofía de la historia que, si bien conservó motivos marxistas, superó conceptos tales como la lucha de clases o la idea de una transformación revolucionaria de la sociedad. Para ello, se afirma, resultó fundamental la 
observación de Horkheimer en cuanto a que la razón instrumental -que justifica el statu quo social e histórico- resultaba incapaz de dar cuenta de la función desempeñada por el desarrollo de la ciencia y de la técnica en la dominación de la Naturaleza y en el aumento de las fuerzas represivas (Ureña, 1978: 4850; Ferrater, 1994: 1395). Más aún, para Velasco (2000: 12) la constatación de la pérdida de la dimensión revolucionaria del proletariado, así como otras críticas a posiciones centrales del marxismo ortodoxo, aparecieron pronto entre los maestros de la primera Escuela.

Así, sobre la base de esta idea fundamental, desde Horkheimer y Adorno hasta Marcuse y Habermas, se ha desarrollado entre los frankfurtianos la tendencia a una denuncia de los procesos falsamente liberadores y emancipadores -entre los que incluyen algunas tendencias del marxismo (Habermas, 1987: 360-368)- por lo que la búsqueda de la razón que pudiera dar cuenta de las decisiones a tomar y que fuera igualmente opuesta al totalitarismo y al liberalismo, ha sido el norte de muchas de las investigaciones y especulaciones de los discípulos de la Escuela de Frankfurt (Habermas, 1987: 216-273). Por ello, aunque algunos de estos han desembocado en un pesimismo respecto a las posibilidades de la razón y de la historia, como Horkheimer, Adorno y Marcuse (Ureña, 1978: 47-55; Cortina, 1986:79-99; Habermas, 1989; 1985:135-162) otros en cambio, alejándose del formalismo positivista y del históricamente rígido empirismo, han intentado abrirse camino hacia una racionalidad más abierta, menos negativa y pesimista, unida a una teoría general de la comunicación humana (Habermas,1985b; 1992: 136146; 2001). Como el propio Habermas (1990: 43) afirma, no se puede olvidar que $E l$ hombre unidimensional era un libro profundamente pesimista, no solo expresión de un estado de ánimo pesimista, sino también un libro negativista en sus supuestos básicos, atenidos por entero a la línea de pensamiento iniciada por la Dialéctica de la Ilustración.

Ahora, establecido el vínculo existente entre la Escuela de Frankfurt 
y Habermas, resulta interesante observar cuál es su ubicación dentro de ella y la visión del autor sobre la misma. Al respecto, se ha destacado (Velasco, 2000:10) la renuencia de Habermas para adscribir su obra, sin más, al círculo de los antiguos frankfurtianos puesto que su relación con los fundadores de la Escuela no puede ser tildada como una continuación de la matriz teórica originaria, entre otros motivos, porque no se puede sostener tal continuidad.

El propio Habermas no se reconoce seguidor de la Escuela o discípulo de tales maestros, por lo que no ha intentado ni conservar, ni transmitir, y menos repetir, el legado de la primera generación de la Escuela de Frankfurt. Él se siente, más bien, seguidor de la tradición crítica del marxismo occidental y, como tal, ha tratado de liberarse de la imagen teleológica del mundo que -a su juicio- venía contenida en los presupuestos criptonormativos de la filosofía materialista de la historia sostenida por la Escuela. Por ello, en lugar de la razón de las fuerzas productivas, y en último lugar, de las ciencias de la naturaleza y de la técnica, Habermas confía más en la fuerza productiva de la comunicación, que se manifiestan con más claridad en las luchas y movimientos sociales de liberación. Razón comunicativa que, para él, ya se hizo valer también por los movimientos burgueses de emancipación, en las luchas por la soberanía popular y los derechos fundamentales. Sedimentando las instituciones del Estado democrático de derecho y las instituciones de la opinión pública burguesa (Habermas, 1991: 122).

Para Habermas, su teoría social se aleja de la primera generación de la Escuela de Frankfurt, además, por el rol e importancia que le asignan ambos a la cultura en el capitalismo tardío. Esto es, la diferencia de perspectiva con la que responden la pregunta de por qué el capitalismo, pese a las tendencias a la crisis que le son inmanentes, podía y puede seguir desarrollándose y estabilizándose.

La respuesta de los primeros es acudir a la simple teoría ortodoxa sobre la cultura de masas y su dependencia de la estructura económica, que responde a la idea programática de Horkheimer sobre el análisis de una ciencia 
social interdisciplinar, la "unidad en la pluralidad", cuyo propósito central era investigar «la racionalización como cosificación», valiéndose para ello de los diferenciados medios que les ofrecían las distintas disciplinas sociológicas. Como explica el propio Habermas (1992b: 534-535), hasta principio de los años cuarenta, el trabajo del Instituto de Investigación Social estuvo dominado en lo esencial por seis temas: a) De las formas de integración de las sociedades postliberales; b) De la socialización en la familia y del desarrollo del yo; c) De los medios de comunicación de masas y de la cultura de masas; d) De la psicología social de la protesta paralizada y acallada; e) De la teoría del arte, y f) De la crítica del positivismo y de la ciencia. Antes de que la «crítica de la Razón Instrumental» volviera a reducir el proceso de cosificación a una tema de filosofía de la historia, Horkheimer y su círculo habían convertido las «abstracciones reales» en objeto de investigación empíricas.

Habermas en cambio, postula que, partiendo de la constatación de que hoy las crisis del capitalismo se han consolidado y normalizado -al precio de la persistencia del desempleo y de la marginación, de la exclusión de la clase relativamente impotente pero mantenida por el Estado social- cuanto mejor integrada socialmente esté la mayoría de quienes tienen empleo, tanto más importante se tornan los factores culturales para explicar dichas desestabilizaciones pasajeras pues estas son -más bien- la expresión de una revolución cultural. De allí, el interés por las evoluciones culturales, por la religión, por la conciencia moral y jurídica, por el arte moderno y, en general, por el cambio cultural de las orientaciones valorativas. Pues, mientras más se nutran y dependan de estas la capacidad de integración de la sociedad, tanto más obligadas se ven la política y la administración pública, con el fin de mantener la lealtad de la población, a conectar con ámbitos culturales que no le resultan habituales y de fácil acceso, y tanto más dependientes se tornan del potencial de aprendizaje y de experiencias almacenado en el denominado capital cultural (Habermas, 1991:123-124). 
Por todo ello, para Habermas a diferencia de la primera generación, hoy se puede ver con más claridad que las horas del paradigma productivista están contadas: por mucho que se le pueda objetar al capitalismo, lo que no se le puede objetar es la generación de las más importantes fuerzas productivas modernas representadas por la ciencia y la técnica. Pero, si algo amenaza al capitalismo son sus propios éxitos: esa compenetración sin sutura de fuerzas productivas y fuerzas destructivas, la síntesis en que se enlaza un crecimiento sin ninguna orientación cualitativa y un ciego desarrollo de las fuerzas productivas. (Habermas, 1991:125). En palabras de Habermas (1991):

El progreso técnico no hace más que impulsar la aceleración de la historia y la movilización de espacios: la racionalización de los mundos de la vida de las primeras sociedades burguesas, articulados en términos de estamentos profesionales, discurrió por sus propios carriles, digamos, culturales. Desde principios del siglo XIX la actitud hacia lo históricamente transmitido se quiebra y torna reflexiva. Penetra cada vez más en la conciencia de la población el que las tradiciones, aún las más sagradas, no son nada caído del cielo, sino que aguardan a ser sometidas a examen, a ser objeto de apropiación y a ser proseguidas selectivamente (126).

Por otra parte, también constituye un signo de diferenciación en la obra de Habermas la serie de acometidas desarrolladas por el autor entre los años 19731976 con el fin de elaborar un enfoque que entiende como de reconstrucción del materialismo histórico, que se refleja en una serie de trabajos reunidos en su obra homónima. Para Fernández (1997: 38) con tales trabajos se inicia en Habermas no solo un interés en desarrollar una teoría del obrar comunicativo sino una importante diferencia con sus antecesores a la hora de valorar el rol de los medios de comunicación de masas y su influencia en los receptores.

En lo que nos interesa, este trabajo de Habermas viene a plantear una profunda revisión crítica al marxismo occidental (Quiroga, 2007: 256), bajo el intento de elaborar un enfoque teórico entendido conceptualmente no como una 
simple restauración o un renacimiento sino como una verdadera reconstrucción. Esto es, como el acto de desmontar una teoría para luego recomponerla con una nueva forma, con el único objeto de alcanzar mejor la meta que ella misma se ha impuesto, ya que, para Habermas, tal debe ser el modo de actuar respecto de una teoría que en algunos puntos necesita una revisión, pero cuya capacidad estimulante dista mucho de estar agotada. No es una restauración porque ello significaría el retorno a un estado inicial ya corrompido y su interés por la obra de Marx y Engels no es dogmático ni tampoco histórico-filosófico. Tampoco es un renacimiento, pues ello querría decir la renovación de una tradición sepultada y, para Habermas, el marxismo no tiene ninguna necesidad de semejante cosa (Habermas, 1981: 9).

Muestras de su reconstrucción son, entre otras, su abandono del paradigma de la producción en pro del de la comunicación, a través de su concepto de trabajo social y de la historia del género humano, con la correspondiente sustitución del destinatario de la teoría: la sociedad en su conjunto y no solo el proletariado; su negación a concebir las formas burguesas de moralidad y legalidad como meros reflejos ideológicos del modo de producción capitalista y verlos, más bien, como expresiones de un proceso irreversible de aprendizaje colectivo (Habermas, 1981:131-180).

En este sentido, para Habermas, su investigación sobre la Teoría de la Acción Comunicativa tiene como propósito introducir una teoría que dé razón de los fundamentos normativos de una teoría crítica de la sociedad. Esta teoría representa una alternativa a la filosofía de la historia sobre la que se asentaba el materialismo histórico, que resulta ya insostenible, y a la que se mantuvo ligada la antigua teoría crítica de la primera generación de la Escuela de Frankfurt. Para el autor, su Teoría de la acción comunicativa constituye un marco dentro del cual puede retomarse aquel proyecto de estudios interdisciplinarios sobre el tipo selectivo de racionalización que representa la modernización capitalista (Habermas, 1992b: 562-563). 
Lo alternativo de la teoría de Habermas, a este respecto, es tratar por primera vez desde esta perspectiva comunicativa las tendencias a la juridización, las cuatro hornadas de juridización, y su análisis de la juridización en el Estado intervencionista y su ambivalencia como garantía de libertad y privación de libertad. Ello porque para Habermas (1992b).

La teoría de la cosificación tardo-capitalista, reformulada en categorías de sistema/mundo de la vida, necesita, pues, ser completada con un análisis de la modernidad cultural que sustituya a la anticuada teoría de la conciencia de clase. El objetivo de ese análisis no sería servir a la crítica ideológica, sino explicar el empobrecimiento cultural y la fragmentación de la conciencia cotidiana; en vez de andar ansiosamente tras las evanescentes huellas de una conciencia revolucionaria, su objetivo sería averiguar las condiciones que permitieran la reconexión de la cultura racionalizada con una comunicación cotidiana que ha menester de tradiciones vivas que la nutran (502).

Con ello, según Habermas (1992b), la teoría de la sociedad ya no necesitaría asegurarse de los contenidos normativos de la cultura burguesa, del arte y del pensamiento filosófico por vía indirecta, es decir, por vía de una crítica ideológica, por el contrario, con el concepto de razón comunicativa, de una razón inmanente al uso del lenguaje cuando este uso se endereza al entendimiento, vuelve a considerar a la filosofía capaz de cumplir tareas sistemáticas y a exigirle ese cumplimiento. Así, las ciencias sociales pueden entablar relaciones de cooperación con una filosofía que asume como tarea la de realizar el trabajo preliminar para una teoría de la racionalidad:

Con la cultura moderna sucede lo mismo que con la Física de Newton y de sus sucesores; lo mismo que la ciencia, tampoco la cultura necesita de una fundamentación filosófica. [...] Con la ciencia moderna, con el derecho positivo y con las éticas profanas regidas por principios, con el arte autónomo y la institucionalización de la crítica de arte, cristalizaron, sin que la filosofía interviniera en ello, tres momentos de la razón. De esta forma, los hijos e hijas de la modernidad tampoco necesitan pasar por la Crítica de la razón pura ni por la de la razón práctica para aprender a dividir la tradición cultural, de acuerdo con estos tres aspectos 
de racionalidad, en cuestiones de verdad, en cuestiones de justicia o en cuestiones de gusto, ya proseguida en esa dirección. [...] Las éticas cognitivistas hacen abstracción de los problemas de la vida buena y se concentran en los aspectos estrictamente deónticos, susceptibles de universalización, de modo que de «el bien» solo quedan las cuestiones relativas a la justicia (563).

De allí, la acción comunicativa, comienza a enlazarse de manera original y propositiva, en la propuesta jurídico-procedimental de Habermas (1988). En sus palabras:

Utilizo la expresión «acción comunicativa» para aquellas manifestaciones simbólicas (lingüísticas y no-lingüísticas) con que los sujetos capaces de lenguaje y acción entablan relaciones con la intención de entenderse sobre algo y coordinar así sus actividades. [...] En la acción comunicativa los participantes se orientan al entendimiento o se atienen al consenso previamente alcanzado. Incluso el éxito de la acción, a que en cada caso aspiran, sólo puede alcanzarse a través del entendimiento o consenso obtenido. Cuando se logra un entendimiento, conduce entre los participantes a un acuerdo. El acuerdo no puede forzarlo ninguna de las partes; el que se produzca depende de la oferta de una y de la postura que frente a esa oferta adopte la otra. La oferta que el acto de habla de uno comporta, tendrá buen suceso si el otro la acepta. Desde el punto de vista de la teoría de la acción no interesa en primer término el significado de un acto de habla (o de una manifestación no lingüística equivalente), es decir, no interesa tanto aquello acerca de lo cual puede producirse un acuerdo, no interesa tanto el contenido de un consenso, como las condiciones formales de la obtención de ese consenso (353-354).

Por todo lo anterior, el que la principal fuente del pensamiento de Habermas provenga de su condición de miembro de la llamada segunda generación de la Escuela de Frankfurt no debe llamar a equívocos, ya que, sin perjuicio de que con su reflexión teórica ha orientado la acción política de movimientos sociales y partidos políticos de izquierda de todo el mundo, el autor no es un mero repetidor del legado filosófico de Marx. Muy por el contrario, su obra posee un clarísimo perfil personal caracterizado por la lucidez para unificar, en forma coherente y original, en un marco teórico y conceptual propio, sistemas y propuestas teóricas ajenas. 
De ahí que su principal singularidad emane de una actitud global calificada por Velasco (2000: 9-10) como el rasgo distintivo y afirmativo de su pensamiento- consistente en no limitarse solo al momento negativo de la crítica, sino adoptar una estrategia intelectual que posibilite plantear propuestas constructivas de forma racional. Entre ellas, que la teoría social debe identificar en las estructuras normativas de las sociedades -especialmente en su práctica política- partículas y fragmentos de una razón existente, para luego poder reconstruirlos reflexivamente con el fin de que sea factible remitirse a ellos como potencial emancipador. Rasgo normativo que se manifestaría no solo en su diagnóstico de las patologías sociales de la modernidad sino también en su terapia para tal situación, esto es, su propuesta democrática de un ámbito social de comunicación y discusión libre de coacciones.

Dicha propuesta normativa-discursiva, que si bien aparece ya esbozada y en desarrollo a lo largo de toda su obra (Habermas, 1981: 233; 1986: 15; 1987; 1992: 316; 1992b:111; 1994: 87; 1998), tiene su máxima expresión (Velasco, 2000, 2007; García, 2000:357) en su texto más completo y maduro al respecto: Facticidad y Validez.

\section{La Teoría Crítica}

Se ha establecido (Jay, 1986:83-87; Cortina, 1986:47) que el origen de la denominada Teoría Crítica -en adelante TC- estaría en un trabajo de 1937, titulado Teoría tradicional y teoría crítica, donde Max Horkheimer formuló y elaboró sus rasgos programáticos fundamentales, dando forma con ello a la principal teoría de los miembros de la primera generación de la Escuela de Frankfurt. Asimismo, se señala como un trabajo esencial para entender los postulados de la misma el desarrollado por Theodor Adorno y Max Horkheimer, en 1947, titulado Dialéctica de la Ilustración.

En razón de los modestos objetivos de este trabajo no analizaré todos 
los planteamientos de la teoría crítica (Ureña, 1978: 21-55; Jay, 1986: 151, 285; Cortina, 1986: 79; Requejo, 1991; Carretero, 2006) sino solo algunos de los que, a mi juicio, influyeron más directamente en la obra de Habermas.

Según Estrada (1990: 19) el punto de partida fundamental de la TC es su concepción social del hombre y su concepción acerca de que los postulados de la libertad y de la autonomía del individuo, en la forma defendida por el capitalismo liberal, son conceptos vacíos puesto que al considerarlos en forma abstracta, sin referencia a la sociedad, se les vacía de contenido y se les priva de desarrollo precisamente en el lugar donde mejor podían realizarse: la sociedad. En palabras de Horkheimer (2000), la realidad perceptible para el miembro de la sociedad burguesa, tal como se interpreta en la concepción tradicional del mundo, que se encuentra en interacción con aquélla:

Se presenta al sujeto como un conjunto de facticidades; el mundo está ahí, y debe ser aprehendido. El pensar organizador de cada individuo pertenece al conjunto de las relaciones sociales que tienden a adaptarse del modo más adecuado posible a las necesidades (34).

Sin embargo, lo relevante para la nueva TC no es solo demostrar esta constatación metodológica propia de la antigua teoría (Horkheimer, 2000: 2333) sino el postular que entre el individuo y la sociedad existe, en este punto, una diferencia esencial. Según afirma Horkheimer (2000):

El mismo mundo que para el individuo es algo existente en sí, que él contempla y debe aprehender, es al mismo tiempo, en la forma en que existe y subsiste, un producto de la praxis social general. Lo que percibimos en nuestro entorno [...] lleva en sí el sello de la elaboración. Los hombres son un resultado de la historia no solo en sus vestidos y en su conducta, en su figura y en su forma de sentir, sino que también el modo en que ven y oyen es inseparable del proceso vital social tal como se ha desarrollado durante milenios. Los hechos que los sentidos nos presentan están socialmente preformados de dos modos: a través del carácter histórico del objeto percibido y a través del carácter histórico del órgano percipiente. Ambos son naturales pero también están configurados por la actividad humana (35). 
La diferencia está dada, para Horkheimer, en que el individuo se experimenta a sí mismo en la percepción como receptivo y pasivo. Por lo que la oposición entre actividad y pasividad, que se presenta en la teoría del conocimiento como el dualismo de sensibilidad y entendimiento, no es válida para la sociedad en la misma medida que para el individuo.

Esta diferencia en la existencia del hombre y la sociedad es una expresión de la escisión que hasta ahora era propia de las formas históricas de la vida social. La existencia de la sociedad o bien descansa sobre la opresión inmediata, o bien es el resultado ciego de fuerzas en conflicto, pero en todo caso no es el resultado de la espontaneidad consciente de individuos libres (35).

Por esta razón, concluye Horkheimer, el significado de los conceptos de actividad y pasividad cambia, según se apliquen a la sociedad o al individuo. En el sistema económico la actividad de la sociedad es ciega y concreta, y la del individuo es abstracta y consciente.

Como bien señala Estrada, (1990: 20-21) esta concepción del hombre de la TC no implica, sin embargo, su definición solo como un animal político, sino más bien una definición marxista de él, esto es, la de un ser alienado, ya que, al estudiar su realidad y llegar a una comprensión total de la misma, se descubre como un individuo que vive como una partícula aislada dentro de la sociedad y sus relaciones interpersonales están afectadas por la cosificación impersonal. Por ello, afirma, la finalidad de la TC será transformar la sociedad y emancipar al hombre, salvándolo de su propia alienación.

De aquí surge otro importante presupuesto de la TC (Cortina, 1986: 203); la lucha contra la cosificación, la reificación y la alienación del hombre, denunciando las causas de la misma en la sociedad contemporánea. Como señala Ureña (1978: 47), el hombre que vegeta en la sociedad capitalista desarrollada ni siquiera es consciente de la irracionalidad en que está inmerso 
pues ha llegado al extremo de estar alienado de su propia alienación.

En este sentido Horkheimer (2000) afirma que la oposición al concepto tradicional de teoría no surge de la diversidad de objetos estudiados sino más bien del rol del sujeto. Es decir, para la TC, los hechos, al surgir del trabajo en sociedad, no son sólo externos como para el investigador tradicional:

En la medida en que los estados de cosas dados en la percepción se conciben como productos que pertenecen esencialmente al dominio del hombre y que $[. .$.$] deberían quedar bajo control humano en el futuro, tales estados$ de cosas pierden su carácter de mera facticidad. [...] Mientras que el experto en una disciplina considera la realidad social y sus productos en tanto que científico como algo externo, y en tanto que ciudadano defiende sus intereses en dicha realidad social por medio de artículos políticos, la afiliación a partidos o a organizaciones benéficas y la participación en las elecciones, sin reunir estos y otros comportamientos en su propia persona $[\ldots]$ en cambio el pensamiento crítico está motivado [...] por el intento de trascender realmente esta tensión, de superar la oposición entre la conciencia de los fines, la espontaneidad y racionalidad de las que el individuo se hace cargo y las relaciones del proceso de trabajo que son el sustrato de la sociedad. El pensamiento crítico contiene un concepto del hombre que entra en conflicto consigo mismo mientras no se produzca esta identidad. Cuando la acción determinada por la razón pertenece al hombre individual, la praxis social dada, que configura la existencia hasta en sus mínimos detalles, es inhumana, y esta inhumanidad revierte sobre todo lo que se realiza en la sociedad (44).

Por ello, para Horkheimer (2000: 52), las teorías que se acreditan en la construcción de máquinas, en las organizaciones militares o en exitosas piezas de cine siempre culminan en alguna forma de consumo. En cambio, no hay ejemplos de cómo se podría consumir el futuro del que se ocupa el pensamiento crítico. No obstante, pese a todo, reconoce que la idea de una sociedad futura como comunidad de hombres libres, tal como la hacen posible los medios técnicos de que disponemos, tiene un significado en el que debemos depositar nuestra confianza. Por ser la comprensión de que el desgarramiento y la irracionalidad se pueden eliminar, y de cómo es posible hacerlo bajo las condiciones dominantes.

Por ello, para Horkheimer y Adorno (1994: 54-55) la caída del hombre 
actual bajo el dominio de la naturaleza es inseparable del progreso social. Para ello, el aumento de la productividad económica, que por un lado crea las condiciones para un mundo más justo, procura, por otro, al aparato técnico y a los grupos sociales que disponen de él, una inmensa superioridad sobre el resto de la población, de forma tal que el individuo es anulado por completo frente a los poderes económicos. Al mismo tiempo, estos elevan el dominio de la sociedad sobre la naturaleza a un nivel hasta ahora insospechado. Así, en una situación injusta, la impotencia y la ductilidad de las masas crecen con los bienes que se les otorga. La elevación, materialmente importante y socialmente miserable, del nivel de vida de los que están abajo se refleja en la hipócrita difusión del espíritu. Siendo su verdadero interés la negación de la cosificación, el espíritu se desvanece cuando se consolida como un bien cultural y es distribuido con fines de consumo. El alud de informaciones minuciosas y de diversiones domesticadas corrompe y entontece al mismo tiempo.

Así, para la TC (Horkheimer, 2000: 57), existe solo una verdad, por lo que no se puede atribuir en el mismo sentido a cualquier otra teoría y praxis los predicados positivos de honradez y consecuencia interna, racionalidad, y aspiración a la paz, la libertad y la felicidad. No hay teoría de la sociedad que no contenga intereses políticos, cuya verdad se debe determinar en la actividad histórica concreta, en lugar de hacerlo en una reflexión aparentemente neutral que, por su parte, no piensa ni actúa.

De aquí surge otro gran postulado de la TC, heredado a Habermas, y que tiene su origen remoto en la Crítica de la Economía Política de Marx (Ureña, 1978: 21-28). Esto es, la crítica a la irracionalidad y a la barbarie de la sociedad contemporánea de mediados del siglo XX. La constatación de que los hombres viven en condiciones materiales que están muy lejos de corresponder a las posibilidades técnicas y económicas existentes en sus sociedades, encontrándose, además, sumidos en una atmósfera político-social 
de flagrante contradicción con los ideales de libertad y de justicia universalmente reconocidos. Crítica a través de la cual la TC buscó impulsar a los hombres a la conquista de las posibilidades materiales y espirituales existentes y a la construcción de una sociedad racional, relegada hasta entonces a vivir en sus fantasías (Horkheimer, 2000: 52 - 62 - 76).

Así, su crítica apunta a que la forma fundamental de la economía de mercancías históricamente dada, sobre la que se asienta la historia moderna, contiene en sí misma los antagonismos internos y externos de la época, los reproduce continuamente, cada vez con mayor crudeza, y tras un período de incremento, de despliegue de las fuerzas humanas, de emancipación del individuo; tras la expansión gigantesca del poder humano sobre la naturaleza, finalmente obstaculiza el desarrollo posterior y empuja a la humanidad a una nueva barbarie (Horkheimer, 2000: 62). Más aún, en la obra la dialéctica de la Ilustración, (Adorno-Horkheimer, 1994: 51-59) la TC vino a denunciar la existencia de una dialéctica oculta que conduce a la razón, confundida en la búsqueda de condiciones de vida auténticamente humanas, a zozobrar en nuevas formas de barbarie, ya que, el objetivo de la Ilustración de liberar a los hombres del miedo y convertirlos en soberanos, se difumina bajo las calamidades que triunfan por todas partes.

Por estas razones, como bien señala Cortina (1986: 47-50, 201-202), la TC no busca analizar la sociedad como un puro objeto de estudio externo, como un dato cuyo mecanismo de funcionamiento hubiera que descubrir y describir. Por el contrario, lo que intenta es perforar esa capa exterior de funcionamiento para llegar hasta la visión de una sociedad que va produciendo sus propias formas de vida, que va transformando las condiciones reales bajo las que los hombres van configurándose a sí mismos. Su crítica está situada en unas determinadas condiciones socio-económicas y, por tanto, no es neutral, se sabe movida por un interés emancipatorio, por una disconformidad con la injusticia. Por ello, su tarea consiste en sacar a la luz lo reprimido en la historia 
y en desenmascarar las patologías sociales mediante algún criterio normativo.

En este punto aparece tímidamente en la TC lo que, a mi juicio, será posteriormente un tema que caracterizará la obra de Habermas y que, dada la forma en que lo trata y desarrolla, lo vinculará sustancialmente con la misma: el Derecho. Horkheimer, a propósito del análisis del concepto clase social y su relación con la propiedad jurídica de los medios de producción (2000: 68-74), se refiere al Derecho en términos positivos e instrumentales.

Horkheimer constata que (2000: 69), con el rápido proceso de concentración y centralización del capital que, mediado por el despliegue de la técnica, ha tenido lugar desde el siglo XX, los propietarios jurídicos han sido apartados de la dirección de las gigantescas empresas que se van formando y que absorben sus fábricas, con lo que la dirección se autonomiza frente a los títulos jurídicos de propiedad. Con ello, aparecen los industriales, los dirigentes de la economía y el hecho de conservar, al principio, la mayor parte de la propiedad de sus consorcios se vuelve inesencial pues aparecen poderosos directivos particulares que dominan sectores enteros de la industria poseyendo una mínima parte de la propiedad de las fábricas que dirigen. Lo relevante de este proceso económico es que, para Horkheimer (2000), trae consigo un cambio en la función del aparato jurídico y político, y de las ideologías:

Sin que haya cambiado en lo más mínimo la definición jurídica de la propiedad, los propietarios se tornan cada vez más impotentes frente a los directivos y sus equipos. La capacidad de disponer directamente de los medios de producción de las gigantescas empresas da a la dirección una superioridad tal que [...] apenas se puede pensar en una victoria de sus oponentes, los propietarios, en el caso de que éstos promuevan un pleito contra la dirección a causa de cualesquiera diferencias de opinión. La influencia de la dirección, que en un principio sólo se relacionaba con instancias jurídicas y administrativas inferiores, acaba extendiéndose también a las instancias superiores, y por último al Estado y su organización de poder (70).

Por ello, para Horkheimer (2000: 70) cada vez más pierde peso la idea de un derecho independiente frente a la generalidad y provisto de un contenido fijo. 
Más aún cuando, del mismo sector social que mantiene el poder de disposición sobre los medios de producción, surgen doctrinas políticas según las cuales la propiedad improductiva y los ingresos parasitarios deberían desaparecer.

Más aún, Horkheimer (2000: 71) no cree que con la eliminación de todo derecho que posea un contenido determinado, eliminación condicionada por la concentración del poder económico y que se consuma en las condiciones de los estados autoritarios, desaparezca, junto con la ideología, un factor cultural que en modo alguno tiene solo un aspecto negativo, sino que también tiene otro positivo. Para él, al considerar estas transformaciones de la estructura interna de la clase de los empresarios, aparecen también diferencias en otros conceptos de la TC. Por ello, la dependencia de la cultura respecto de las relaciones sociales se debe transformar junto con estas hasta en sus detalles, si es cierto que la sociedad es un todo.

Estos postulados entroncan, a su vez, con la crítica al positivismo postulado por la TC que, en general, puede relacionarse, como bien señala Estrada (1990: 33), con su crítica a las ideologías. Ello, porque Teoría tradicional y TC presenta como trasfondo el claro enfrentamiento entre esta y las teorías positivistas, tan en boga en su época. Como bien se señala (Ureña, 1978: 23-25; Ferrater, 1994: 3477), el punto de partida de la crítica es que el reduccionismo gnoseológico del positivismo lleva, según la TC, a la glorificación de los hechos y, con ello, a la petrificación del status quo imperante en la sociedad. Así, contra esta actitud hacia la ciencia - a veces ingenuamente practicada, pero que se repite explícita y conscientemente en la época en la que nace la TC- es la que la Escuela de Frankfurt proyecta sus planteamientos, atacando al cientificismo moderno por absolutizar la actitud positivista de las ciencias como único método científico y convertir la metodología de las Ciencias de la Naturaleza como el modelo ideal que han de seguir también las Ciencias Sociales, incluyendo en ello también al propio Derecho (Durán, 2006: 59-65).

Lo importante es que, precisamente en seguimiento de las ideas de 
Marx, la Escuela de Frankfurt denuncia esta actitud como ideológica, esto es, como encubridora de los aspectos inhumanos de la sociedad contemporánea y contraria a toda reflexión crítica, asimilando el rol de la Economía Política clásica - en provecho y defensa de los poderes opresores de su tiempo- con la actitud cientificista, que constituye un soporte ideológico para los poderes opresores de su tiempo. Así, con su obra, Horkheimer se constituye en el verdadero pionero en la denuncia de uno de los presupuestos más ideológicos del mundo de la ciencia, gracias al que el empirismo metodológico del quehacer científico se convierte en un esfuerzo por delimitar la ciencia, la ética y la política en circunstancias que, por el contrario, las Ciencias Sociales tienen un rol político basado en la inexistencia de datos empíricos puros o independientes de su contexto social (Estrada, 1990: 48-49).

De esta manera Horkheimer (2000: 59) concibe también el desarrollo de la vida en la lógica discursiva o lógica del entendimiento. Para esta lógica, que este hombre sea ahora un niño y luego un adulto solo puede significar que existe un núcleo fijo que permanece igual a sí mismo: este hombre. A él se adhieren sucesivamente ambas propiedades, la infancia y la madurez. Para el positivismo, nada en absoluto permanece idéntico, sino que primero hay un niño, más tarde un adulto, y ambos son dos complejos diferentes de hechos. Esta lógica es incapaz de recoger el hecho de que un hombre cambie y sin embargo permanezca idéntico a sí mismo.

Asimismo, como bien se señala (Ureña, 1978: 47; Cortina, 1986: 64), la TC se opone al optimismo histórico por el progreso moral del hombre y sus posibilidades de emancipación por la realización del proyecto Ilustrado. Pues se ha perdido el verdadero sentido de la modernidad al considerar a la razón como razón instrumental, olvidando su dimensión moral. Además, para la TC la especial correlación existente en la sociedad moderna entre; nivel de desarrollo técnico, grado de concentración del poder y medios disponibles para 
la manipulación ideológica a través de la cultura de masas, es el mayor peligro para la conciencia crítica y para la emancipación humana. Peor aún, contra las predicciones de Marx, aunque la clase obrera no obtiene poder, goza de importantes mejoras materiales; el capitalismo sobrelleva las crisis y los países socialistas desmienten la tesis de que a mayor justicia, más libertad. Incluso el fenómeno de la cosificación y reificación, propio de las sociedades capitalistas, también se produce en las socialistas.

Como señalan Adorno y Horkheimer (1994):

En el actual quiebre de la civilización burguesa se ha hecho cuestionable no solo la organización sino el sentido mismo de la ciencia [...] La incesante autodestrucción de la Ilustración, obliga al pensamiento a prohibirse incluso la más mínima ingenuidad respecto a los hábitos y las tendencias del espíritu del tiempo. Si la opinión pública ha alcanzado un estadio en el que inevitablemente el pensamiento degenera en mercancía y el lenguaje en elogio de la misma, el intento de identificar semejante depravación debe negarse a obedecer las exigencias lingüísticas e ideológicas vigentes, antes de que sus consecuencias históricas universales lo hagan del todo imposible. Si los obstáculos fueran solamente aquellos que derivan de la inconsciente instrumentalización de la ciencia, la reflexión sobre las cuestiones sociales podría unirse a las tendencias en oposición a la ciencia oficial. Pero también estas han sido afectadas por el proceso global de producción y han cambiado no menos que la ideología a la que se debían. [...] Por ello, les sucede lo que siempre sucedió al pensamiento triunfante: en cuanto abandona voluntariamente su elemento crítico y se convierte en mero instrumento al servicio de lo existente, contribuye sin querer a transformar lo positivo que había hecho suyo en algo negativo y destructor (51-52).

Por estas ideas, la crítica de la TC al positivismo se transformó, a fines de los años cuarenta del siglo pasado, como bien señala Velasco (2000: 15), en una mordaz acusación contra los efectos patológicos del modelo occidental de racionalidad y en una denuncia del peligro totalitario que conlleva apelar dogmáticamente a lo racional.

Por otra parte, como afirma Ureña (1978: 24-25) la TC de la Escuela de Frankfurt es, como la obra de Marx, unidad de teoría y praxis. Es teoría, porque la realidad histórica ha negado los postulados de Hegel y de Marx pues el nivel 
humano anhelado por todos sigue estando por alcanzar y solo puede volver a anticiparse teóricamente dentro de una actitud crítica. Es praxis porque lleva dentro de sí el impulso por suprimir la dependencia ciega e inhumana del hombre en las relaciones materiales. Es, a la vez, teoría y praxis, porque su crítica solo puede lograrse si, como teoría, es capaz de responder a las necesidades reales y realizables de los hombres -en un momento histórico determinado- y de entrar e incrustarse en sus conciencias e íntimas intenciones de actuación práctica. Por ello, en contra de la tradicional Filosofía Social, incapaz de ponerse en relación a una praxis verdadera y orientada solo hacia una actuación tecnificada, la TC intenta conservar una genuina relación con la praxis auténtica, no analizando la sociedad como un objeto exterior a sí misma ni describiendo sus leyes de funcionamiento como los de un mecanismo existente, sino comprendiéndose a sí misma como un elemento catalizador necesario propio del mismo contorno social y vital que estudia, analizando ese contorno totalitario y opresor desde la perspectiva de su posible abolición.

Para la teoría crítica, esta estructura o modo de pensar es producto de la idea tradicional y dominante de ciencia, desarrollada en una sociedad dominada por las técnicas de producción industrial. Por ello, el paso a otro tipo de ciencia no es un mero avance teórico ni una simple reestructuración intelectual, es un cambio histórico que constituye también un cambio en el proceso social (Ferrater, 1994: 3477).

Claramente Habermas recoge esta idea y la desarrolla latamente en su obra Teoría y Praxis, (1987:49-86) bajo el epígrafe La doctrina clásica de la política en su relación con la filosofía social. Al respecto, ya en su introducción, establece que tales investigaciones, orientadas en su mayoría históricamente, pretenden desarrollar la idea de una teoría de la sociedad concebida con intención práctica. Tipo de teoría de la sociedad, configurada originalmente por Marx que, para Habermas (1987), se caracteriza por el hecho de ser reflexiva en una doble perspectiva, por una doble relación entre teoría y praxis: 
Investiga, por una parte, el contexto histórico de constitución de una situación de interés a la que aún pertenece la teoría, por así decirlo, a través del acto de conocimiento; $y$, por otra parte, investiga el contexto histórico de acción sobre el que la teoría puede ejercer una influencia que orienta la acción. En un caso se trata de la praxis social que en tanto que síntesis social hace posible el conocimiento; en el otro de una praxis política que conscientemente aspira a subvertir el sistema de instituciones existente. Por ello, en virtud de la reflexión sobre su contexto genético la crítica se diferencia lo mismo de la ciencia que de la filosofía. [...] Razón por la que una filosofía social que se ha tornado monológica no puede ponerse en relación con la praxis sino solo con una acción intencionalracional dirigida por medio de recomendaciones técnico-sociales (13-14).

En este marco, y sin perjuicio del propio análisis y observaciones que Habermas realiza de la primera TC (1992b: 527-562), debe señalarse que las críticas que le formula son fundamentales para entender el giro y desarrollo posterior de su propia obra, ya que, tal como él mismo señala (1992b: 542), no obstante ellas, hace suyos algunos de los principales propósitos del programa de investigación interdisciplinario de la antigua TC, constituyéndolo en un ejemplo a seguir. Especialmente, en los estudios posteriores donde pretende aclarar tres aspectos entre teoría y praxis: el empírico de la relación entre ciencia, política y opinión pública en los sistemas sociales del capitalismo tardío; el epistemológico de la conexión de conocimiento e interés y el metodológico de una teoría de la sociedad que debe poder tomar sobre sí el papel de la crítica (Habermas, 1987: 14).

En este punto, Habermas (1992b: 539) observa críticamente el hecho que los procesos de cosificación de la conciencia solo se convirtieron en un objeto de investigación empírico una vez que la teoría del valor perdió toda función fundamentadora. Pero, con ello, también quedó abandonado el contenido normativo del derecho natural racional conservado en la teoría del valor. Por ello, el contenido normativo del concepto de cosificación había que obtenerlo ahora del potencial de racionalidad de la cultura moderna. De ahí 
que la TC mantuviera una relación afirmativa con el arte y con la filosofía de la época burguesa. Las artes, la literatura clásica, la vanguardia literaria y musical, se convierten en objeto preferido de una crítica ideológica que se impone a sí misma como tarea el separar los contenidos trascendentes del arte auténtico, de los componentes afirmativos ideológicamente consumidos de los ideales burgueses.

Teniendo presente lo anterior, se entiende porque Habermas señala (1992b: 539-540), que la discusión con la teoría tradicional realizada por la TC, en términos de crítica ideológica, solo pudo proponerse el objetivo de recuperar el contenido de verdad de los conceptos y problemas filosóficos captar su contenido sistemático- por venir sustentada por la filosofía marxista de la historia, es decir, por la convicción de que las fuerzas productivas desarrollan una fuerza objetivamente explosiva. Esto es, porque el programa de investigación de la antigua TC se sostenía en la confianza en el potencial racional de la cultura burguesa, que bajo la presión del desarrollo de las fuerzas productivas se desataría en movimientos sociales. Sin esta teoría de la historia, no es posible mantener una crítica constante en torno a las figuras del espíritu objetivo, capaz de distinguir entre aquello que el hombre y las cosas pueden ser y aquello que fácticamente son, puesto que sin ella la crítica se ve abandonada a los variables criterios que, contingentemente, cada época histórica pone a su disposición.

Sin embargo, para Habermas (1992b: 540), paradójicamente Horkheimer, Marcuse y Adorno, merced precisamente a sus trabajos de crítica ideológica, reforzaron su opinión de que en las sociedades post-liberales la cultura pierde su autonomía y queda incorporada -en las formas desublimadas que adopta en la cultura de masas-al engranaje del sistema económico-administrativo, en el que el desarrollo de las fuerzas productivas, incluso el propio pensamiento crítico, aparece en una turbia asimilación a su contrario. Por ello, para Habermas, en 
la medida en que para estos autores la sociedad totalmente administrada solo encarnaba una razón instrumental elevada a totalidad, todo lo que existe se transforma en abstracción real y, siendo así, lo atacado y deformado por esas abstracciones tiene necesariamente que sustraerse a toda intervención empírica. De esta forma, para Habermas, la fragilidad de estos fundamentos de filosofía de la historia permite entender por qué este tipo de TC, aun interdisciplinaria, estaba condenada al fracaso, así como por qué sus autores acotaron el programa solo a consideraciones especulativas sobre la dialéctica de la ilustración.

Esta simplificación y pesimismo histórico, para Habermas (1992b: 541), ocurrió porque los presupuestos del Materialismo Histórico sobre la relación dialéctica entre fuerzas productivas y relaciones de producción se habían transformado en enunciados pseudo-normativos sobre una teleología objetiva de la historia. Tal teleología, considerada como la fuerza impulsora de la realización de una razón, se había interpretado de forma equívoca. La vieja TC, por tanto, solo podía acudir a esos fundamentos normativos para su perspectiva de la filosofía de la historia pero ellos eran incapaces de sustentar un programa de investigación empírica. Lo que queda de manifiesto, para Habermas, en la falta de un ámbito objetual de estudio claramente delimitado como es el de la práctica comunicativa cotidiana del mundo de la vida, en la que se encarnan las estructuras de racionalidad y en la que pueden ser identificados los procesos de cosificación.

Así, con esta distinción, Habermas intenta liberar al Materialismo Histórico de su lastre de ser una Filosofía de la historia (1992b: 541-542). Para ello, le aplica dos abstracciones que pueden contribuir a erradicar sus confusiones de categorías, esto es, la del desarrollo de las estructuras cognitivas respecto a la dinámica de los acontecimientos históricos y la de la evolución social respecto a la concreción histórica de las formas de vida. Todo para que dicha filosofía no parta de ideales concretos, inmanentes a las formas de vida legadas por la tradición, sino que se oriente por las posibilidades de procesos 
de aprendizaje, acordes con el nivel de aprendizaje históricamente alcanzado, es decir, renuncie a enjuiciar críticamente y a clasificar normativamente totalidades, formas de vida y culturas, formaciones sociales y épocas históricas en su conjunto. Gracias a ello, para Habermas (1992b: 541), a diferencia de la antigua TC, la teoría de la acción comunicativa puede asegurarse del contenido racional de estructuras antropológicas profundas en un análisis que inicialmente es solo reconstructivo, esto es, que viene planteado en términos ahistóricos. Ese análisis describe estructuras de la acción y del entendimiento, que pueden inferirse del saber intuitivo de los miembros competentes de las sociedades modernas. Ese análisis cierra todo camino de vuelta hacia una filosofía de la historia que, por fuerza, no puede ser capaz de distinguir entre problemas de lógica evolutiva y problemas de dinámica evolutiva.

Por estas ideas, la obra de Habermas, al tomar partido a favor de la razón y los valores, huyendo de la pesimista ortodoxia marxista, impulsa la realización de una investigación teórico-práctica de las posibilidades y límites del capitalismo tardío, resaltando para ello la importancia de la legitimidad y, en lo que nos interesa, del derecho. Ello, porque para Habermas (1986: 169), la creencia en la legalidad parte necesariamente de una creencia, de su fundamentación en la legitimidad. Para él, el procedimiento inobjetable de sanción de una norma, el hecho de que un proceso se ajuste a la formalidad jurídica, únicamente garantiza que las instancias previstas dentro de un sistema político, competentes y acatadas como tales, son responsables por el derecho vigente. Pero esas instancias son parte de un sistema de poder que tiene que estar legitimado en total si es que la legalidad pura ha de considerarse signo de legitimidad. Ello significa que la sola forma técnico-jurídica, la legalidad pura, no puede asegurar su acatamiento, en el largo plazo, si el sistema de poder no puede legitimarse con independencia de su ejercicio ajustado a las formas correctas. 


\section{A modo de conclusión}

De acuerdo con lo desarrollado, y en la línea de lo ya establecido al respecto (McCarthy, 1978; Ureña, 1978; Cortina 1986, 2007; Requejo, 1991; Fernández, 1997; Velasco, 2000, 2007; Vallespín, 2001; Laso, 2004; Carretero, 2006; Quiroga, 2007; Kominek, 2007), creo que la impronta e influencia más palpable que tuvieron en la monumental obra de Habermas, tanto la Escuela de Frankfurt como la TC, se puede apreciar-sobre todo-en el método o forma de pensar heredado y desarrollado por el autor. Esto es, una teoría científica crítica e interdisciplinaria opuesta tanto a la mera especulación filosófico-sociológica como al empirismo positivista, y siempre vinculada a los problemas reales y concretos de su tiempo.

Este método influye, además, en su especial visión sobre la relación hombre-sociedad, preocupada por la permanente denuncia de los procesos falsamente liberadores y emancipadores entre los que incluirá, como digno continuador del espíritu de la Escuela de Frankfurt y de la TC, la crítica a la ideología y, por ello, a algunas tendencias del propio marxismo. Asimismo, de esta impronta crítica deriva su especial visión social del hombre, en la que, aun partiendo de la constatación de estar en presencia de un ser alienado, se da paso a una propuesta que le exige a éste integrarse, transformar la sociedad y emanciparse.

De este espíritu crítico deriva también su visión del Derecho como un instrumento positivo y legitimador que se abre hacia una racionalidad abierta y sustantiva que, unida a su teoría de la comunicación humana, sirve para alejarlo del formalismo positivista y mostrarlo en su función de mediador de los distintos conflictos sociales, propios de la sociedad posmoderna.

Finalmente, gracias a esta forma de pensar de Habermas, heredada de la Escuela de Frankfurt y de la $T C$, sus estudios y su maciza propuesta teórica está orientada hacia y en función de la praxis. Ello, porque tanto en su 
visión de la sociedad y el hombre, como en la del Derecho, construidas desde la realidad que le ha tocado vivir, se expresan en una revalorización positiva de la modernidad, de la Democracia, de los Derechos Humanos y de la juridificación que, más allá de la especulación, de los prejuicios o de la mera ideología, nos presenta una finalidad explicativa, emancipadora y correctiva, basada y dirigida al conocimiento y a la modificación de la praxis.

\section{Referencias}

Adorno, Theodor-Horkheimer, Max. Dialéctica de la Ilustración. Fragmentos filosóficos. Introducción y Traducción Juan José Sánchez. Madrid: Trotta, 1994.

Beck, Ulrich (1998). La sociedad del riesgo. Hacia una nueva modernidad. Barcelona: Paidós.

Carretero, Ángel (2006). "Jürgen Habermas y la Primera Teoría Crítica: encuentros y Desencuentros". Cinta Moebio, 27, 11-26. Disponible en: http://www.moebio.uchile.cl/27/carretero.html

Colom, Francisco (1992). Las caras del Leviatán. Una lectura política de la Teoría Crítica. Barcelona: Anthropos.

Cortina, Adela (1986). Crítica y utopía. Prólogo de Javier Muguerza. Madrid: Cincel.

(2007). "Jürgen Habermas: Luces y sombras de una política deliberativa". Revista de Ciencias Sociales, $\mathrm{n}^{\circ} 52$ Homenaje a Jürgen Habermas. Facultad de Derecho y Ciencias Sociales. Universidad de Valparaíso, 49-73.

Durán, Mario (2006). Introducción a la Ciencia jurídico-penal contemporánea. Ediciones Jurídicas de Santiago: Santiago.

Estrada, Juan Antonio (1990). La teoría crítica de Max Horkheimer. Del socialismo ético a la resignación. Granada: Universidad de Granada.

Fernández, Sergio (1997). “Habermas y la Teoría Crítica de la sociedad. Legado y diferencias en teoría de la comunicación”. Cinta Moebio, 1, 27-41. Disponible en: www.moebio.uchile.cl/01/frprin03.html 
Ferrater Mora, José (1994). Diccionario de Filosofía. 4 Tomos. Edición revisada, actualizada y aumentada por la Cátedra Ferrater Mora del pensamiento contemporáneo de la Universidad de Girona, dirigida por Josep Maria Terricabras y supervisada por Priscilla Colin Ferrater Mora. Barcelona: Círculo de Lectores.

García, Juan Antonio (2000). "Habermas y el Derecho" en, de él mismo (Coord.). El Derecho en la teoría social. Diálogo con catorce propuestas actuales, pp. 357-381. Madrid: Dykinson, 2000.

Habermas, Jürgen (1981). La reconstrucción del materialismo histórico. Traducción de Jaime Nicolás Muñiz y Ramón García Cotarelo. Madrid: Taurus.

(1985a). El discurso filosófico de la modernidad (Doce lecciones). Traducción de Manuel Jiménez Redondo. Madrid: Taurus.

- (1985b). Conciencia moral y acción comunicativa. Barcelona: Península.

(1986). Problemas de legitimación en el capitalismo tardío. $2^{\mathrm{a}}$ Reimpresión de la $1^{a}$ Edición Traducida de José Luis Etcheberry. Buenos Aires: Amorrortu.

(1987). Teoría y praxis. Estudios de filosofía social. Traducción de Salvador Mas Torres y Carlos Moya Espí. Madrid: Tecnos.

(1989). Conocimiento e interés. Versión castellana de Manuel Jiménez, José F. Ivars y Luis Martín Santos. Revisada por José Vidal Beneyto. Madrid: Taurus.

(1991). La necesidad de revisión de la izquierda. Introducción y Traducción de Manuel Jiménez Redondo. Madrid: Tecnos.

(1992a). La teoría de la acción comunicativa I, racionalidad de la acción y racionalización social. Traducción de Manuel Jiménez Redondo. Madrid: Taurus.

(1992b). La teoría de la acción comunicativa II, Crítica de la razón funcionalista. Traducción de Manuel Jiménez Redondo. Madrid: Taurus. - (1998). ¿Cómo es posible la legitimidad por vía de legalidad? 
DOXA, 5, 21-45.

(2001). Facticidad y validez. Sobre el derecho y el Estado democrático de derecho en términos de teoría del discurso. Introducción y traducción, sobre la $4^{\mathrm{a}}$ edición revisada, de Manuel Jiménez Redondo. Madrid: Trotta. (2002). “¿Por qué la Unión Europea necesita un marco Constitucional?". Boletín Mexicano de Derecho Comparado, XXXV(105), 947-978.

Horkheimer, Max (2000). Teoría tradicional y teoría crítica. Introducción de Jacobo Muñoz. Barcelona: Paidós.

Jay, Martin (1986). La imaginación dialéctica: una historia de la Escuela de Frankfurt y del Instituto de Investigación Social (1923-1950). Madrid: Taurus.

Kominek, Andrea (2007). "La teoría Habermasiana: de sus herencias frankfurtianas a la superación del paradigma cartesiano". Revista tecnología e sociedade, 3 (4), 15-32.

Laso, Silvana (2004). "La importancia de la teoría crítica en las ciencias sociales". Espacio Abierto, 13 (3), 435-455. Disponible en: http://www. redalyc.org/articulo.oa? $\mathrm{id}=12213305$.

Letelier, Raúl (2011). "La Justicia Constitucional en el pensamiento de Jürgen Habermas”. Estudios Constitucionales, 9 (2), 377-394.

McCarthy, Thomas (1978). La Teoría Crítica de Jürgen Habermas. Madrid: Tecnos.

Quiroga, Patricio (2007). "El marxismo de Habermas". Revista de Ciencias Sociales, 52 Homenaje a Jürgen Habermas. Facultad de Derecho y Ciencias Sociales. Universidad de Valparaíso, 251-266.

Requejo, Ferran (1991). Teoría crítica y estado social. Neokantismo y socialdemocracia en J. Habermas. Barcelona: Anthropos.

Silva, Jesús-María (2001). La expansión del Derecho penal. Aspectos de la politica criminal en las sociedades postindustriales. Madrid: Civitas.

Ureña, Enrique (1978). La teoría crítica de la Sociedad de Habermas. La crisis 
de la sociedad industrializada. Madrid: Tecnos.

Vallespín, Fernando (2001). "Habermas en doce mil palabras”. Claves de Razón Práctica, 114, 53-63.

Velasco, Juan Carlos (2000). La teoría discursiva del derecho. Sistema jurídico y democracia en Habermas. Madrid: BOE-Centro de estudios políticos y constitucionales.

(2007). "Los Derechos Humanos en la democracia deliberativa o la superable contraposición entre liberalismo y republicanismo". Revista de Ciencias Sociales, 52 Homenaje a Jürgen Habermas. Facultad de Derecho y Ciencias Sociales. Universidad de Valparaíso, 479-512. 